\title{
Fasting plasma glucose and risk factor assessment: Comparing sensitivity and specificity in identifying gestational diabetes in urban black African women
}

\author{
L M Dickson, ${ }^{1 *}$ FCP (SA); E J Buchmann, ${ }^{2 \star} \mathrm{PhD}$; C Janse van Rensburg, ${ }^{3} \mathrm{MSc}$; A Norris, ${ }^{1} \mathrm{PhD}$ \\ ${ }^{1}$ MRC Developmental Pathways to Health Research Unit, Department of Paediatrics, Faculty of Health Sciences, University of the Witwatersrand, \\ Johannesburg, South Africa \\ ${ }^{2}$ Department of Obstetrics and Gynaecology, Faculty of Health Sciences, University of the Witwatersrand, York Road, Parktown, Johannesburg, \\ South Africa \\ ${ }^{3}$ Biostatistics Unit, South African Medical Research Council, Pretoria, South Africa \\ * Joint senior authors
}

Corresponding author: L M Dickson (lynnsaymd@diabeteswest.co.za)

Background. Identifying women with gestational diabetes mellitus (GDM) allows interventions to improve perinatal outcomes. A fasting plasma glucose (FPG) level $\geq 5.1 \mathrm{mmol} / \mathrm{L}$ is $100 \%$ specific for a diagnosis of GDM. The International Association of Diabetes and Pregnancy Study Groups acknowledges that FPG $<4.5 \mathrm{mmol} / \mathrm{L}$ is associated with a low probability of GDM.

Objectives. The validity of selective screening based on the presence of risk factors was compared with the universal application of FPG $\geq 4.5 \mathrm{mmol} / \mathrm{L}$ to identify women with GDM. FPG $\geq 4.5 \mathrm{mmol} / \mathrm{L}$ or the presence of one or more risk factors was assumed to indicate an intermediate to high risk of GDM and therefore the need for an oral glucose tolerance test (OGTT).

Methods. Consecutive black South African (SA) women were recruited to a 2-hour 75 g OGTT at 24 - 28 weeks' gestation in an urban community health clinic. Of 969 women recruited, 666 underwent an OGTT, and of these 589 were eligible for analysis. The glucose oxidase laboratory method was used to measure plasma glucose concentrations. The World Health Organization GDM diagnostic criteria were applied. All participants underwent a risk factor assessment. The $\chi^{2}$ test was used to determine associations between risk factors and a positive diagnosis of GDM. The sensitivity and specificity of a positive diagnosis of GDM were calculated for FPG $\geq 4.5 \mathrm{mmol} / \mathrm{L}, \mathrm{FPG} \geq 5.1 \mathrm{mmol} / \mathrm{L}$, and the presence of one or more risk factors.

Results. The prevalence of overt diabetes mellitus and GDM was $0.5 \%$ and $7.0 \%$, respectively. Risk factor-based selective screening indicated that 204/589 (34.6\%) of participants needed an OGTT, but 18/41 (43.9\%) of positive GDM diagnoses were missed. Universal screening using the FPG threshold of $\geq 4.5 \mathrm{mmol} / \mathrm{L}$ indicated that $152 / 589(25.8 \%)$ of participants needed an OGTT, and $1 / 41(2.4 \%)$ of positive diagnoses were missed. An FPG of $\geq 5.1 \mathrm{mmol} / \mathrm{L}$ identified $36 / 41$ (87.8\%) of GDM-positive participants. The sensitivity and specificity of the presence of one or more risk factors were $56 \%$ and $67 \%$, respectively. The sensitivity and specificity of FPG $\geq 4.5 \mathrm{mmol} / \mathrm{L}$ were $98 \%$ and $80 \%$, respectively.

Conclusions. Universal screening using FPG $\geq 4.5 \mathrm{mmol} / \mathrm{L}$ had greater sensitivity and specificity in identifying GDM-affected women and required fewer women to undergo a resource-intensive diagnostic OGTT than risk factor-based selective screening. A universal screening strategy using FPG $\geq 4.5 \mathrm{mmol} / \mathrm{L}$ may be more efficient and cost-effective than risk factor-based selective screening for GDM in black SA women.

S Afr Med J 2020;110(1):21-26. https://doi.org/10.7196/SAMJ.2020.v110i1.14089

The World Health Organization (WHO) estimates that $16 \%$ of pregnancies are affected by gestational diabetes mellitus (GDM) globally. ${ }^{[1]}$ Although there is a paucity of data on South African (SA) women, GDM prevalences of $9.1 \%$ and $25.8 \%$ have recently been reported. ${ }^{[2,3]}$ Identifying affected women allows interventions to improve perinatal outcomes. ${ }^{[4]}$ Both screening strategies and diagnostic thresholds for GDM attract controversy. ${ }^{[5]}$ The International Association of Diabetes and Pregnancy Study Groups (IADPSG) advocates universal screening for GDM, but the WHO recommends that screening strategies be based on disease burden and the availability of resources. ${ }^{[4,6]}$ Risk factor-based selective screening for GDM is currently applied in SA. ${ }^{[7]} \mathrm{A}$ selective screening strategy may fail to identify a high proportion of women affected by GDM. ${ }^{[8-10]}$ In addition to being inadequate, this strategy is difficult to implement and women at risk may not be offered screening, even in well-resourced settings. ${ }^{[11,12]}$
An alternative to selective or universal application of the oral glucose tolerance test (OGTT) is universal screening using the fasting plasma glucose (FPG) level. According to the WHO 2013 recommendation, ${ }^{[4]}$ an elevated FPG of $\geq 5.1 \mathrm{mmol} / \mathrm{L}$ is $100 \%$ specific for a GDM diagnosis. However, the sensitivity of this diagnostic threshold varies between countries and ethnicities. ${ }^{[13]}$ The Hyperglycemia and Adverse Pregnancy Outcome (HAPO) study group has suggested that 'in populations in which FPG is diagnostic in more than half of those with GDM, it may be reasonable to perform an accurately measured FPG as an initial step, reserving a full OGTT for those with a non-diagnostic FPG. ${ }^{[13]}$ The IADPSG acknowledges the low probability of GDM and the low risk of adverse outcomes in the HAPO study cohort associated with FPG $<4.5 \mathrm{mmol} / \mathrm{L}$. ${ }^{[14]}$ Women with an $\mathrm{FPG}<4.5 \mathrm{mmol} / \mathrm{L}$ are therefore at low risk of GDM and may not require an OGTT. Because women with an FPG $\geq 4.5 \mathrm{mmol} / \mathrm{L}$ are at intermediate to high risk for 
GDM, they would require an OGTT. This FPG threshold has been suggested for use in low-resource settings, as it reduces the number of women requiring an OGTT. Use of this threshold would also avoid missed diagnoses in populations where the sensitivity of the FPG may be suboptimal or unknown. ${ }^{[14-16]}$

\section{Objectives}

To compare the utility of this universally applied dual FPG threshold, namely that $\geq 4.5 \mathrm{mmol} / \mathrm{L}$ indicates that formal screening is required and $<4.5 \mathrm{mmol} / \mathrm{L}$ rules out GDM. The sensitivity and specificity were compared with the current standard practice of risk factorbased selective screening in identifying urban black African women affected by GDM.

\section{Methods \\ Ethical considerations}

The University of the Witwatersrand Human Research Ethics committee reviewed and approved the study protocols (ref. no. M150365). The Johannesburg District Department of Health granted permission to conduct this study in Soweto, Johannesburg (ref. no. 2015-16/031). All participants gave written informed consent.

\section{Design}

This cross-sectional, pragmatic, prospective study took place at a single urban community health clinic (CHC) between April 2016 and May 2017. Consecutive women were recruited at their first antenatal clinic visit. Women at $<28$ weeks' gestation were eligible for inclusion, and we excluded those aged $<18$ years and those known to have type 1 or type 2 diabetes mellitus. Gestational age was determined by the clinic nurse as part of usual care. There were no ultrasound facilities on site. Study procedures were conducted within the usual functioning of the antenatal service of the $\mathrm{CHC}$.

\section{Participants}

Data gathered from all participants included risk factors for GDM as defined by the SA National Department of Health (NDoH). ${ }^{[7]}$ These include maternal obesity (body mass index (BMI) $\geq 35 \mathrm{~kg} / \mathrm{m}^{2}$, which is WHO obesity class $\geq \mathrm{II}$ ), maternal age $\geq 40$ years, previous history of GDM, first-degree relative with diabetes mellitus, previous unexplained intrauterine fetal death, previous macrosomic baby, or complications in the current pregnancy including polyhydramnios, fetus large for gestational age or the presence of repeated glycosuria. ${ }^{[5]}$ All participants in the study were of black African ethnicity, in keeping with this clinic's patient profile, so the $\mathrm{NDoH}$ risk factor of being of South Asian descent did not apply. Additional data collected included gestation at the first antenatal visit, parity, cigarette smoking, history of chronic hypertension, and blood pressure and mid-upper arm circumference measurements. ${ }^{[17,18]}$ Participants were frequently unable to recall exact birth weights of their previous babies, so the terms 'small', 'average or 'large' were used instead, as was standard practice at this clinic.

\section{Oral glucose tolerance test}

All participants underwent a 2-hour $75 \mathrm{~g}$ glucose OGTT in the morning after an overnight fast at $24-28$ weeks' gestation. Venous blood samples were collected in tubes containing the glycolytic inhibitor sodium fluoride (BD 454297), and samples were kept on ice ex vivo. The use of sodium fluoride tubes is included in the WHO-recommended OGTT procedure. ${ }^{[19]}$ Typically, there are no on-site laboratories at CHCs in SA. All venous blood samples were delivered to the off-site laboratory, which was $14 \mathrm{~km}$ away, within an hour of completion of the OGTTs. This research laboratory used the glucose oxidase method (RX daytona+; Randox Laboratories, USA) to determine plasma glucose concentrations. On request, the laboratory provided us with its quality control results. At mean glucose concentrations of $6.36 \mathrm{mmol} / \mathrm{L}$ and $15.80 \mathrm{mmol} / \mathrm{L}$, the analytical coefficients of variation (CVs) were $1.85 \%$ and $1.67 \%$, with a bias of $0.35 \%$ and $0.31 \%$, respectively. These quality control results are within the recommendation of the American National Academy of Clinical Biochemistry (NACB) for laboratory measurements of plasma glucose (a CV of $\leq 2.9 \%$ and a bias of $\leq 2.2 \%)$. ${ }^{[20]}$ Trained research staff operated independently from the CHC staff.

\section{Clinical diagnostic criteria}

The WHO 2013 diagnostic criteria, ${ }^{[4]}$ which were endorsed by the Society of Endocrinology, Metabolism, and Diabetes of South Africa (SEMDSA) in 2017, ${ }^{[21]}$ were used to define OGTT cut-offs for a positive GDM diagnosis. Only one plasma glucose abnormality in the 2-hour OGTT is necessary for a positive diagnosis of GDM. GDM is defined as a plasma glucose concentration of $5.1-6.9 \mathrm{mmol} / \mathrm{L}$ at fasting, $\geq 10.0 \mathrm{mmol} / \mathrm{L}$ at 1 hour of the OGTT or $8.5-10.9 \mathrm{mmol} / \mathrm{L}$ at 2 hours. Diagnostic thresholds for overt diabetes in pregnancy, which indicates probable preconception diabetes, are a plasma glucose concentration $\geq 7.0 \mathrm{mmol} / \mathrm{L}$ at fasting or $\geq 11.0 \mathrm{mmol} / \mathrm{L}$ at 2 hours of the OGTT. Participants diagnosed with overt diabetes or GDM were referred for clinical intervention.

\section{Sample size}

This analysis was part of a research study to assess the feasibility of implementing a universal screening, diagnosis and GDM lifestyle intervention programme in a low-resource urban setting. ${ }^{[22,23]}$ We intended to identify 100 GDM-positive women for the purpose of participating in the GDM lifestyle intervention. Based on an estimated $16 \%$ global prevalence, 625 consecutive participants would need to be recruited.

\section{Statistical analysis}

Categorical variables were described as frequencies and proportions (\%) and continuous variables as means and standard deviations (SDs). The $\chi^{2}$ test was used to determine associations between categorical variables, especially between known risk factors and a positive GDM diagnosis. Fisher's exact test was used in cases where expected frequencies were $<5$. In this analysis, FPG thresholds were retrospectively used to indicate the need for an OGTT, and the categories were low risk $(<4.5 \mathrm{mmol} / \mathrm{L})$, meaning no need for an OGTT, and intermediate to high risk $(\geq 4.5 \mathrm{mmol} / \mathrm{L})$, indicating the need for a formal diagnostic OGTT to determine the presence and extent of dysglycaemia. The sensitivity, specificity, positive predictive values (PPVs), negative predictive values (NPVs), positive likelihood ratios (PLRs) and negative likelihood ratios (NLRs) for a positive GDM diagnosis were calculated for FPG $\geq 4.5 \mathrm{mmol} / \mathrm{L}$ and FPG $\geq 5.1 \mathrm{mmol} / \mathrm{L}$ as well as for the presence of one or more $\mathrm{NDoH}$ defined risk factors for GDM. We also evaluated the utility of a modified NDoH-recommended risk score using BMI $\geq 30 \mathrm{~kg} / \mathrm{m}^{2}$ (obesity class I) rather than the standard BMI $\geq 35 \mathrm{~kg} / \mathrm{m}^{2}$ (obesity class $\geq \mathrm{II}){ }^{[21]} \mathrm{A} p$-value $<0.05$ was assumed to be statistically significant, and $95 \%$ confidence intervals (CIs) are presented where appropriate. Statistical analyses were performed on STATA software version 15 (StataCorp LLC, USA). SAS version 9.4 software (SAS Institute Inc., USA) macro NLEstimate was used to compute modelbased $95 \%$ CIs for the likelihood ratios. 


\section{Results \\ Participants}

Of the 1270 women who attended the antenatal clinic over the 12-month recruitment period of the study, 969 (76.3\%) were willing and eligible to participate. Of the 666 participants who had an OGTT, 589 had a complete data set that was submitted for analysis. The number of women recruited and the reasons for the attrition of participant numbers before data analysis are presented in Fig. 1. Overt diabetes mellitus was identified in 3/589 participants $(0.5 \%)$, and GDM was present in $41 / 589$ (7.0\%) (95\% CI 4.9 - 9.2). The mean (SD) BMI of $26.9(5.8) \mathrm{kg} / \mathrm{m}^{2}$ indicates that, overall, participants in the study were overweight; $57 / 589$ participants $(9.7 \%)$ had a BMI $\geq 35 \mathrm{~kg} / \mathrm{m}^{2}$ and $16 / 589$ (2.7\%) had a BMI $\geq 40 \mathrm{~kg} / \mathrm{m}^{2}$. Six participants were glycosuria-positive on one occasion with no opportunity for repeat glycosuria testing prior to the elective OGTT. Participant characteristics are presented in Table 1.

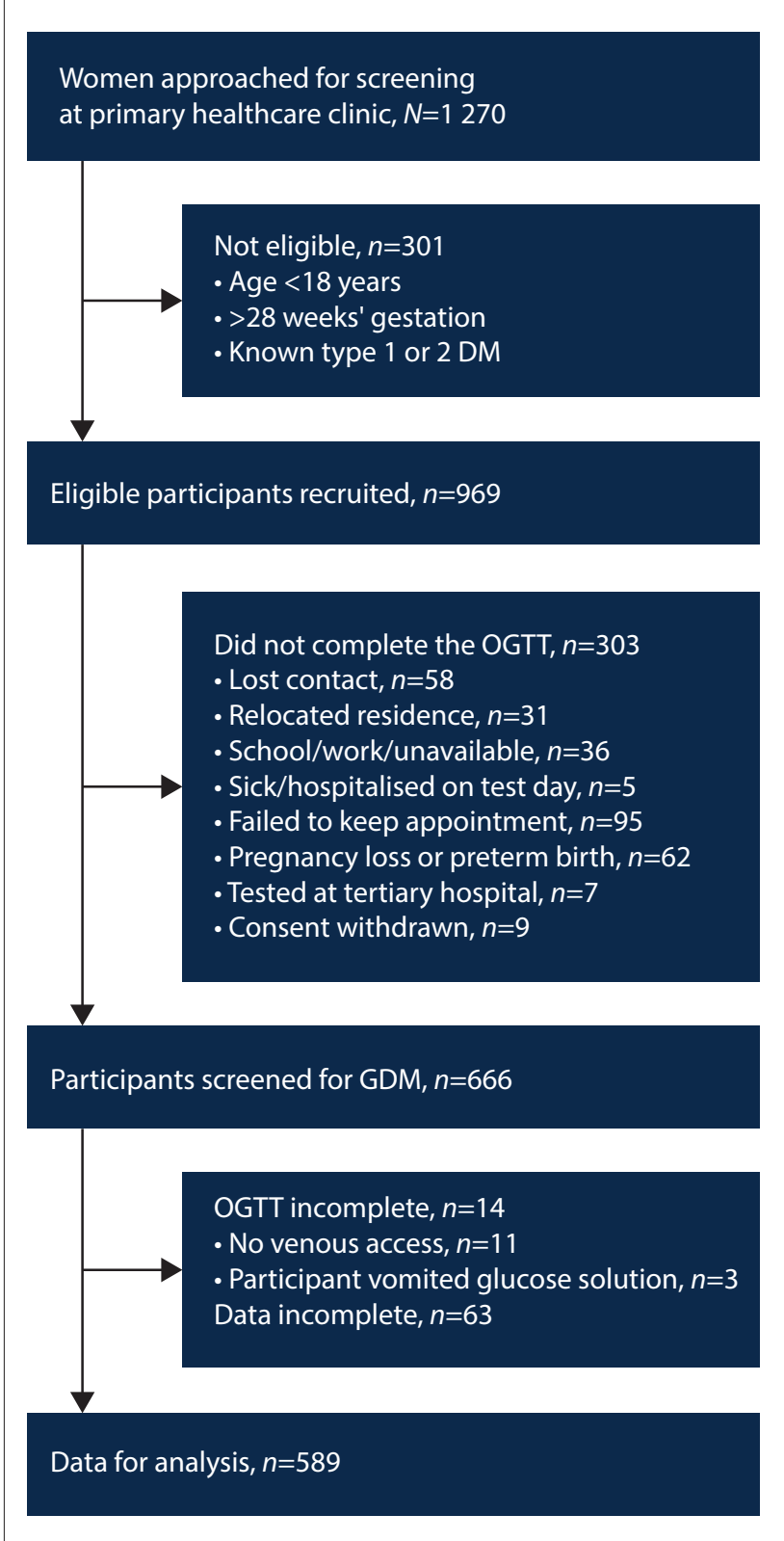

Fig. 1. Consort diagram of participant recruitment. (OGTT = oral glucose tolerance test; $G D M=$ gestational diabetes mellitus.)

\section{Characteristics of GDM-positive women}

GDM-positive women were significantly more overweight than their non-GDM counterparts, with $6.1 \mathrm{~kg}(p=0.017$; 95\% CI 1.1 - 11.1) heavier body weight and a mid-upper arm circumference that was $2.1 \mathrm{~cm}(p=0.004 ; 95 \%$ CI 0.7 - 3.4) greater; they were also older $(p<0.001)$, presented later in pregnancy for their first antenatal visit $(p=0.001)$ and had higher diastolic blood pressure $(p=0.004)$. Of the 41 GDM-positive participants, 5 (12.2\%) were pregnant for the first time and 27 (63.4\%) were pregnant for the third time or more. This higher parity was associated with an increased risk of GDM $(p<0.001)$. Unexpectedly, in this study population, a positive family history of diabetes mellitus was not associated with a positive GDM diagnosis $(p=0.591)$ (Table 1$)$.

\section{Assessment of risk factors}

Based on the current NDoH guidelines (which include BMI $\geq 35 \mathrm{~kg}$ / $\left.\mathrm{m}^{2}\right), 204 / 589(34.6 \%)$ of the participants had one or more risk factors for GDM and would have required an elective OGTT; however, 18/41 GDM-positive cases (43.9\%) would have been missed. At a BMI $\geq 30 \mathrm{~kg} / \mathrm{m}^{2}$, the number of participants requiring an OGTT would have been 262/589 (44.5\%) and the number of missed GDM-positive cases would have been reduced to 12/41 (29.3\%) (Table 2). A selective screening strategy based on the presence of two or more $\mathrm{NDoH}$ risk factors (including BMI $\geq 35 \mathrm{~kg} / \mathrm{m}^{2}$ ) had a sensitivity, specificity, PPV, NPV, PLR and NLR of 23\% (95\% CI 11 - 38), 88\% (95\% CI 86 - 91), 13\% (95\% CI 6 - 22), 94\% (95\% CI 92 - 96), 1.95 (95\% CI 1.05 - 3.63) and $0.88(0.74-1.04)$, respectively. The use of two or more risk factors (including BMI $\geq 35 \mathrm{~kg} / \mathrm{m}^{2}$ ) would have resulted in $33 / 41(80.5 \%)$ of GDM-positive cases being missed.

\section{Assessment of laboratory results}

The mean plasma glucose concentrations at fasting and 60 and 120 minutes of the OGTT were $4.01 \mathrm{mmol} / \mathrm{L}$ (95\% CI 3.95 - 4.07), $5.42 \mathrm{mmol} / \mathrm{L}(95 \%$ CI 5.30 - 5.54) and $5.12 \mathrm{mmol} / \mathrm{L}$ (95\% CI 5.01 $5.23)$, respectively. The number of abnormalities per time point of the OGTT is presented in a Venn diagram (Fig. 2). The use of FPG $\geq 5.1 \mathrm{mmol} / \mathrm{L}$ as a universal screening strategy for GDM would have required $36(6.1 \%)$ of 589 participants to undergo an OGTT; however, 5 (12.2\%) of the 41 GDM-positive participants would have been missed. Based on the dual-threshold screening strategy, if those participants with an FPG $<4.5 \mathrm{mmol} / \mathrm{L}$ were assumed to be at low risk and so were not formally screened, $152(25.8 \%)$ of 589 participants would have required an OGTT and $40(97.6 \%)$ of the 41 with GDM would have been identified (Table 2).

\section{Discussion}

The prevalence of GDM as determined by the glucose oxidase laboratory method in this routine clinical setting in a population of urban black African women attending a single CHC was 7.0\%. Our results have similarities to and differences from recent SA reports of GDM prevalence. Macauley et al. ${ }^{[3]}$ reported a $9.1 \%$ GDM prevalence in a tertiary hospital setting, using a research laboratory (glucose oxidase method), and their participants had a higher risk profile for GDM than participants at the $\mathrm{CHC}$ where this study was conducted. ${ }^{[3]}$ A study by Adam and Rheeder ${ }^{[24]}$ possibly overestimated the GDM prevalence at $25.8 \%$, and one reason for this is that the laboratory bias of $3.65 \%$, which is not within the $\leq 2.2 \%$ recommended by the $\mathrm{NACB},{ }^{[20]}$ would adversely affect the quality of plasma glucose measures.

Importantly, $87.8 \%$ of GDM-positive diagnoses in this study population were based on an elevated FPG. This confirms the 
Table 1. Participant characteristics, with comparison of GDM-positive and GDM-negative women*

\begin{tabular}{|c|c|c|c|c|c|c|c|}
\hline \multirow[b]{2}{*}{ Clinical characteristics } & \multicolumn{2}{|c|}{ All participants $(N=589)$} & \multicolumn{2}{|c|}{ GDM-positive $(N=41)$} & \multicolumn{2}{|c|}{ GDM-negative $(N=548)$} & \multirow[b]{2}{*}{$p$-value } \\
\hline & $N$ & Variable & $N$ & Variable & $N$ & Variable & \\
\hline Age (years), mean (SD) & 589 & $27.8(5.9)$ & 41 & $31.1(6.9)$ & 548 & $27.5(5.7)$ & $<0.001^{\dagger}$ \\
\hline History of chronic hypertension, $n$ (\%) & 588 & $19(3.2)$ & 41 & $1(2.5)$ & 547 & $18(3.3)$ & $1.000^{\ddagger}$ \\
\hline Active smoker (cigarettes), $n$ (\%) & 589 & $21(3.6)$ & 41 & $4(10.0)$ & 548 & $17(3.1)$ & $0.051^{\ddagger}$ \\
\hline Family history of diabetes, $n$ (\%) & 585 & $99(16.9)$ & 40 & $8(20.0)$ & 545 & $91(16.6)$ & $0.591^{5}$ \\
\hline Glycosuria (urine dipstick), $n$ (\%) & 589 & $6(1.0)$ & 41 & $2(4.9)$ & 548 & $4(0.7)$ & - \\
\hline MUAC (cm), mean (SD) & 589 & $29.9(4.4)$ & 41 & $31.8(4.3)$ & 548 & $29.7(4.4)$ & $0.004^{\dagger}$ \\
\hline Body height $(\mathrm{cm})$, mean $(\mathrm{SD})$ & 588 & $162.1(6.6)$ & 40 & $160.7(6.2)$ & 548 & $162.2(6.6)$ & $0.152^{\dagger}$ \\
\hline Body weight (kg), mean (SD) & 589 & $70.7(15.7)$ & 41 & $76.4(15.3)$ & 548 & $70.3(15.7)$ & $0.017^{\dagger}$ \\
\hline BMI $\left(\mathrm{kg} / \mathrm{m}^{2}\right)$, mean $(\mathrm{SD})$ & 588 & $26.9(5.8)$ & 40 & $29.2(5.3)$ & 548 & $26.7(5.8)$ & $0.009^{\dagger}$ \\
\hline Systolic BP (mmHg), mean (SD) & 588 & $122.3(14.9)$ & 41 & $122.8(19.9)$ & 547 & $122.2(14.5)$ & $0.200^{9}$ \\
\hline Diastolic BP (mmHg) & 588 & $72.6(11.0)$ & 41 & $77.4(9.6)$ & 547 & $72.2(11.0)$ & $0.004^{\dagger}$ \\
\hline GA at first visit (weeks), mean (SD) & 589 & $19.1(5.6)$ & 41 & $22.0(4.2)$ & 548 & $18.9(5.6)$ & $<0.001^{\dagger}$ \\
\hline \multicolumn{8}{|c|}{ Number of pregnancies including current, $n(\%)$} \\
\hline$\geq 2$ & 589 & $417(70.8)$ & 41 & $35(85.4)$ & 548 & $382(69.7)$ & $0,033^{\varsigma}$ \\
\hline$\geq 3$ & 589 & $223(37.9)$ & 41 & $27(65.9)$ & 548 & $196(35.8)$ & $<0.001^{\varsigma}$ \\
\hline$>3$ & 589 & $79(13.4)$ & 41 & $9(22.0)$ & 548 & $70(12.8)$ & $0,096^{\varsigma}$ \\
\hline Previous LGA birth, $n(\%)$ & 588 & $43(7.3)$ & 41 & $6(14.6)$ & 547 & $37(6.8)$ & $0.108^{\ddagger}$ \\
\hline Previous stillbirth, $n$ (\%) & 589 & $32(5.4)$ & 41 & $3(7.5)$ & 548 & $29(5.3)$ & $0.481^{\ddagger}$ \\
\hline Previous congenital abnormalities, $n$ & 588 & 0 & 41 & 0 & 548 & 0 & - \\
\hline Previous GDM, $n(\%)$ & 589 & $3(0.5)$ & 41 & $1(2.4)$ & 548 & $2(0.4)$ & - \\
\hline
\end{tabular}

Table 2. Validity measures of GDM screening: universal strategy with FPG $\geq 5.1 \mathrm{mmol} / \mathrm{L}$, universal strategy with FPG $\geq 4.5 \mathrm{mmol} / \mathrm{L}$, selective risk factor-based strategy including a BMI $\geq 30 \mathrm{~kg} / \mathrm{m}^{2}$, and selective risk factor-based strategy including a BMI $\geq 35 \mathrm{~kg} / \mathrm{m}^{2}$

\begin{tabular}{|c|c|c|c|c|}
\hline & \multicolumn{2}{|c|}{$\begin{array}{l}\text { Universal screening based on dual- } \\
\text { threshold FPG v. universal OGTT }\end{array}$} & \multicolumn{2}{|c|}{$\begin{array}{l}\text { Selective screening strategy based } \\
\text { on risk factors v. universal OGTT }\end{array}$} \\
\hline & FPG $\geq 5.1 \mathrm{mmol} / \mathrm{L}$ & $\mathrm{FPG} \geq 4.5 \mathrm{mmol} / \mathrm{L}$ & $\begin{array}{l}1 \text { risk factor(s) } \\
\text { including BMI } \geq 30 \mathrm{~kg} / \mathrm{m}^{2}\end{array}$ & $\begin{array}{l}\geq 1 \text { risk factor(s) } \\
\text { including BMI } \geq 35 \mathrm{~kg} / \mathrm{m}^{2}\end{array}$ \\
\hline Participants, $N$ & 589 & 589 & 589 & 589 \\
\hline True positive, $n$ & 36 & 40 & 29 & 23 \\
\hline False positive, $n$ & 0 & 112 & 233 & 181 \\
\hline True negative, $n$ & 548 & 436 & 315 & 367 \\
\hline False negative, $n$ & 5 & 1 & 12 & 18 \\
\hline Sensitivity, \% (95\% CI) & $88(74-96)$ & $98(87-100)$ & $71(54-84)$ & $56(40-72)$ \\
\hline Specificity, \% (95\% CI) & 100 & $80(76-83)$ & $57(53-61)$ & $67(63-71)$ \\
\hline PPV, \% (95\% CI) & 100 & $26(20-34)$ & $11(8-16)$ & $11(7-16)$ \\
\hline NPV, \% (95\% CI) & $99(98-100)$ & $99(99-100)$ & $96(94-98)$ & $95(93-97)$ \\
\hline PLR (95\% CI) & Undefined & $4.77(3.95-5.60)$ & $1.66(1.30-2.03)$ & $1.70(1.19-2.20)$ \\
\hline NLR (95\% CI) & $0.12^{*}$ & $0.03(-0.03-0.09)$ & $0.51(0.26-0.75)$ & $0.66(0.43-0.89)$ \\
\hline
\end{tabular}

findings of Macauley et al. ${ }^{[3]}$ and Adam and Rheeder ${ }^{[24]}$ that the majority of GDM diagnoses in SA women screened were based on an elevated FPG. The use of FPG alone to screen for GDM is attractive as it is less expensive than a complete OGTT, avoids the need for multiple punctures, reduces laboratory workload, and avoids exposing pregnant women to the sometimes emesis-inducing oral glucose load. ${ }^{[25,26]}$ There is outcomes-based evidence that an elevated FPG alone is comparable to a complete OGTT in predicting largefor-gestational-age infants, and for indicating the need for insulin treatment of GDM. ${ }^{[27-29]}$ Although an FPG $\geq 5.1 \mathrm{mmol} / \mathrm{L}$ is $100 \%$ specific for a diagnosis of GDM, the sensitivity of this diagnostic threshold varies between countries and ethnicities in both lowand high-risk populations. ${ }^{[13,16,30,31]}$ When retrospectively applied to the HAPO study cohort, the mean proportion of GDM-positive diagnoses based on an elevated FPG was 55\% (range 24 - 74\%), and this figure varied between and within countries. ${ }^{[13]}$ The underlying mechanism responsible for this variability is unknown. Sub-Saharan Africa was not included in the HAPO study. The prevalence of 


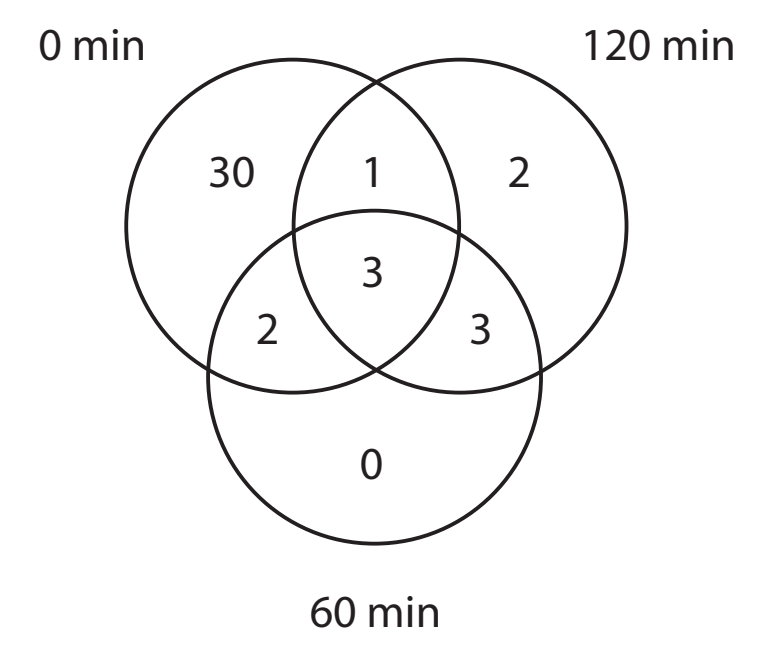

Fig. 2. Venn diagram illustrating the number of positive gestational diabetes mellitus cases identified by the time points of the 2-hour oral glucose tolerance test (World Health Organization 2013 test positivity cut-offs $\mathrm{s}^{[4]}$ ).

elevated FPG in multiethnic SA, affected by historical undernutrition and a current high burden of obesity, is unknown, and the use of a single value of the OGTT may miss GDM-affected women. The low-cost algorithm of a dual-threshold FPG, with $\geq 5.1 \mathrm{mmol} / \mathrm{L}$ (specificity 100\%) used to rule in GDM and $<4.5 \mathrm{mmol} / \mathrm{L}$ to rule it out, was associated with a reduction in the need for a complete OGTT when applied to the HAPO, United Arab Emirates and Brazilian cohorts. ${ }^{[13,15,16]}$ In order to improve accessibility to screening, it may be possible to screen women for GDM with point-of-care testing, thus reducing the need for more expensive and sometimes inaccessible laboratory services. The use of glucometers to screen for and diagnose DM and GDM is endorsed by the $\mathrm{WHO}^{[1]}$ and the International Federation of Gynecology and Obstetrics. ${ }^{[32]}$ The reliable use of selected plasma calibrated glucometers to measure FPG in a universal GDM screening programme in a low-resource SA setting was recently reported. ${ }^{[22]}$

Maternal obesity was strongly associated with a positive GDM diagnosis in this study. SA has a high prevalence of obesity, which is associated with an increased risk of insulin resistance and dysglycaemia. ${ }^{[33,34]}$ Epidemiologically, the prevalence of GDM increases by $0.9 \%$ per one point increase in BMI. ${ }^{[35]}$ In this study, the use of BMI $\geq 30 \mathrm{~kg} / \mathrm{m}^{2}$ was associated with an increased sensitivity compared with a BMI $\geq 35 \mathrm{~kg} / \mathrm{m}^{2} .^{[36]}$ Based on the current screening strategy of risk factor-based selective screening, a high proportion of SA women may require an OGTT, posing a potentially overwhelming burden to existing healthcare and laboratory services. The low sensitivity and specificity of a risk factor assessment to identify SA women with GDM in this study confirms the findings of Adam and Rheeder. ${ }^{[2]}$ The low reliability of risk factor-based selective screening in SA women is aligned with international findings that almost half of GDM-affected women will be missed by selective screening based on conventional risk factors. ${ }^{[6,32]}$ In 2017, SEMDSA adopted the WHO 2013 diagnostic thresholds for GDM, with a suggestion that a universal screening strategy could be implemented only in wellresourced settings in SA. ${ }^{[21]}$ A previous report suggests that ruraldwelling SA women may be at high risk of diabetes in pregnancy. ${ }^{[38]}$ Ideally, equal access to GDM screening should be available to all pregnant women, whether in a private or state healthcare setting, whether urban or rural dwelling, and regardless of ethnicity.
Prior to the WHO revision of GDM diagnostic thresholds in 2013, there was evidence that plasma glucose concentration abnormalities at all time points of the OGTT could predict the need for insulin therapy. ${ }^{[39]}$ There are no prediction models for which GDM-affected women are likely to need oral hypoglycaemic agents or insulin treatment to restore euglycaemia during pregnancy. In addition, increases in fasting and 2-hour plasma glucose concentrations are associated with an increased risk of developing overt diabetes in later years. ${ }^{[40]}$ For this reason, in the event that a GDM diagnosis is made based on an elevated FPG, it may be necessary to perform a complete OGTT.

\section{Study strengths and limitations}

This translational research project was conducted within the usual functioning of a $\mathrm{CHC}$, which equates to routine care rather than a research clinical setting. Our participants were urban black African women attending the antenatal service of a single urban $\mathrm{CHC}$, so our results may not be generalisable beyond this population profile. The sample size and the low GDM prevalence of 7.0\% (95\% CI 4.9 9.2) were insufficient to provide robust estimates of the sensitivity of the FPG screening threshold of $\geq 4.5 \mathrm{mmol} / \mathrm{L}$. Further studies in more diverse patient populations and clinical settings are needed to confirm these results.

\section{Conclusions}

A universally applied FPG threshold of $\geq 4.5 \mathrm{mmol} / \mathrm{L}$, as an indicator of intermediate to high risk of GDM improved sensitivity and reduced the number of women needing to undergo the unpleasant, poorly reproducible and resource-intensive OGTT compared with the current practice of risk factor-based selective screening.

\section{Research highlights}

Overt diabetes and gestational diabetes prevalences were $0.5 \%$ and $7.0 \%$, respectively.

- Selective risk factor screening indicated that $34.6 \%$ of women needed an OGTT, but missed $43.9 \%$ of GDM.

- Universally applied FPG $\geq 5.1 \mathrm{mmol} / \mathrm{L}$ identified $87.8 \%$ of GDMpositive women.

- Universally applied FPG $\geq 4.5 \mathrm{mmol} / \mathrm{L}$ indicated that $25.8 \%$ of women needed an OGTT but missed 2.4\% of GDM.

Declaration. This original research article forms part of LMD's PhD thesis. ${ }^{[22,23]}$

Acknowledgements. The Johannesburg District Department of Health granted permission to conduct this study at the $\mathrm{CHC}$ in Soweto. We are grateful to the participants and the $\mathrm{CHC}$ staff for their support of the project. The sustained efforts of our research assistant, Ms Nandi Mtshali, were essential to the completion of the study on schedule.

Author contributions. LMD and EJB are joint senior authors. LMD, EJB, SAN: methodology. LMD: data collection and had full access to all data during the study. LMD, EJB, CJvR, SAN: data analysis. LMD: wrote the manuscript. EJB, CJvR, SAN: reviewed and edited the manuscript. Funding. The work reported was made possible through funding by the South African Medical Research Council through its Division of Research Capacity Development under the SAMRC Clinician Researcher (MD, $\mathrm{PhD}$ ) Scholarship Programme from funding received from the South African National Treasury. The contents are the sole responsibility of the authors and do not necessarily represent the official views of the SAMRC or the funders. SAN is supported by the Department of Science and 
Technology and the National Research Foundation Centre of Excellence in Human Development at the University of the Witwatersrand, Johannesburg.

Conflicts of interest. None.

1. World Health Organization. Global Report on Diabetes 2016. Geneva: WHO, 2016. https://apps.who int/iris/bitstream/handle/10665/204871/9789241565257_eng pdffisessionid=6DA85A77F5D63C1E19 int/iris/bitstream/handle/10665/204871/9789241565257_eng.p

2. Adam S, Rheeder P. Screening for gestational diabetes mellitus in a South African population Prevalence, comparison of diagnostic criteria and the role of risk factors. S Afr Med J 2017;107(6):523527. https://doi.org/10.7196/SAMJ.2017.v107i6.12043

3. Macaulay S, Ngobeni M, Dunger DB, Norris SA. The prevalence of gestational diabetes mellitus amongst black South African women is a public health concern. Diabetes Res Clin Pract 2018;139:278287. https://doi.org/10.1016/j.diabres.2018.03.012

4. World Health Organization. Diagnostic Criteria and Classification of Hyperglycaemia First Detected in Pregnancy. Geneva: WHO, 2013. https://apps.who.int/iris/bitstream/handle/10665/85975/WHO NMH_MND_13.2_eng.pdf?sequence=1 (accessed 10 February 2015).

5. Sacks DB, Coustan DR, Cundy T, Donovan L, Hod M. Gestational diabetes mellitus: Why the controversy? Clin Chem 2018;64(3):431-438. https://doi.org/10.1373/clinchem.2016.266577

6. International Association of Diabetes and Pregnancy Study Groups Consensus Panel. International Association of Diabetes and Pregnancy Study Groups recommendations on the diagnosis and classification of hyperglycemia in pregnancy. Diabetes Care 2010; 33(3):676-682. https://doi. classification of hype

7. National Department of Health, South Africa. Guidelines for Maternity Care in South Africa: National Department of Health, South Africa. Guidelines for Maternity Care in South Africa:
A Manual for Clinics, Community Health Centres and District Hospitals. 2015;117-119. http://www. A Manual for Clinics, Community Health Centres and District Hospitals. 2015;117-119. http://www.
health.gov.za/index.php/2014-03-17-09-09-38/policies-and-guidelines/category/230-2015p (accessed health.gov.za/index

15 December 2017).
8. Mwanri AW, Kinabo J, Ramaiya K, Feskens EJM. Gestational diabetes mellitus in sub-Saharan Africa: Systematic review and meta-regression on prevalence and risk factors. Trop Med Int Health 2015;20(8):983-1002. https://doi.org/10.1111/tmi.12521

9. Olagbuji BN, Atiba AS, Olofinbiyi BA, et al.; Gestational Diabetes Study Group-Nigeria. Prevalence of and risk factors for gestational diabetes using 1999, 2013 WHO and IADPSG criteria upon implementation of a universal one-step screening and diagnostic strategy in a sub-Saharan African population. Eur J Obstet Gynecol Reprod Biol 2015;189:27-32. https://doi.org/10.1016/j. ejogrb.2015.02.030

10. Veeraswamy S, Vijayam B, Gupta VK, Kapur A. Gestational diabetes: The public health relevance and approach. Diabetes Res Clin Pract 2012;97(3):350-358. https://doi.org/10.1016/..diabres.2012.04.024

11. Murphy NM, McCarthy FP, Khashan AS, et al. Compliance with National Institute of Health and Care Excellence risk-based screening for gestational diabetes mellitus in nulliparous women. Eur J Obstet Excellence risk-based screening for gestational diabetes mellitus in nulliparous w
Gynecol Reprod Biol 2016;199:60-65. https://doi.org/10.1016/j.ejogrb.2016.01.044

12. Di Cianni G, Gualdani E, Berni C, et al. Screening for gestational diabetes in Tuscany, Italy: A population study. Diabetes Res Clin Pract 2017;132:149-156. https://doi.org/10.1016/j.diabres.2017.08.003

13. Sacks DA, Hadden D, Maresh M, et al.; HAPO Study Cooperative Research Group. Frequency of gestational diabetes mellitus at collaborating centers based on IADPSG consensus. Diabetes Care 2012;35(3):526-528. https://doi.org/10.2337/dc11-164

4. Agarwal MM, Weigl B, Hod M. Gestational diabetes screening: The low-cost algorithm. Int J Gynecol Obstet 2011;115(Suppl 1):S30-S33. https://doi.org/10.1016/S0020-7292(11)60009-X

15. Agarwal MM, Dhatt GS, Punnose J, Koster, G. Gestational diabetes in a high-risk population: Using the fasting plasma glucose to simplify the diagnostic algorithm. Eur J Obstet Gynecol Reprod Biol 2005;120(1):39-44. https://doi.org/10.1016/j.ejogrb.2004.07.034

16. Trujillo J, Vigo A, Reichelt A, Duncan BB, Schmidt MI. Fasting plasma glucose to avoid a full OGTT in the diagnosis of gestational diabetes. Diabetes Res Clin Pract 2014;105(3):322-326. https://doi. in the diagnosis of gestational
org $/ 10.1016 /$ i.diabres.2014.06.001

17. Lamain-de Ruiter M, Kwee A, Naaktgeboren CA, et al. External validation of prognostic models to predict risk of gestational diabetes mellitus in one Dutch cohort: Prospective multicentre cohort study. predict risk of gestational diabetes mellitus in one Dutch
BMJ 2016;354:i4338. https://doi.org/10.1136/bmj.i4338

18. Fakier A, Petro G, Fawcus S. Mid-upper arm circumference: A surrogate for body mass index in pregnant women. S Afr Med J 2017;107(7):606-610. https://doi.org/10.7196/SAMJ.2017.v107i7.12255

19. World Health Organization. Definition and Diagnosis of Diabetes Mellitus and Intermediat Hyperglycemia: Report of a WHO/IDF Consultation. Geneva: WHO, 2006. http://www.who.int/ diabetes/publications/diagnosis_diabetes2006/en/index.html (accessed 10 February 2015)
20. Sacks DB, Arnold M, Bakris GA, et al. Guidelines and recommendations for laboratory analysis in the diagnosis and management of diabetes mellitus. Diabetes Care 2011;34(6):e61-e99. https://doi. the diagnosis and manag

21. Society for Endocrinology, Metabolism and Diabetes of South Africa Type 2 Diabetes Guidelines Expert Committee. The 2017 SEMDSA Guideline for the Management of Type 2 Diabetes Guideline Committee. J Endocr Metab Diabetes S Afr 2017;22 (1,Suppl 1):S1-S196.

22. Dickson LM, Buchmann EJ, Janse van Rensburg C, Norris SA. Accuracy of five plasma calibrated glucometers to screen for and diagnose gestational diabetes mellitus in a low resource clinic setting. J Clin Transl Endocrinol 2018;16:100174. https://doi.org/10.1016/j.jcte.2018.12.003

23. Dickson LM, Buchmann EJ, Janse van Rensburg C, Norris SA. The impact of differences in plasma glucose between glucose oxidase and hexokinase methods on estimated gestational diabetes mellitus prevalence. Sci Rep 2019;9(1):7238. https://doi.org/10.1038/s41598-019-43665-x

24. Adam S, Rheeder P. Evaluating the utility of a point-of-care glucometer for the diagnosis of gestational diabetes. Int J Gynecol Obstet 2018;141(1):91-96. https://doi.org/10.1002/ijgo.12399

25. Agarwal MM, Punnose J, Dhatt GS. Gestational diabetes: Problems associated with the oral glucose tolerance test. Diabetes Res Clin Pract 2004;63(1):73-74. https://doi.org/10.1016/j. diabres.2003.08.005

26. Nielsen KK, de Courten M, Kapur A. The urgent need for universally applicable simple screening procedures and diagnostic criteria for gestational diabetes mellitus - lessons from projects funded by the World Diabetes Foundation. Glob Health Action 2012;5(1). https://doi.org/10.3402/gha. v5i0.17277

27. Shen S, Lu J, Zhang L, et al. Single fasting plasma glucose versus 75 -g oral glucose-tolerance test in prediction of adverse perinatal outcomes: A cohort study. EBioMedicine 2017;16:284-291. https:// doi.org/10.1016/j.ebiom.2017.01.02

28. Miailhe G, Kayem G, Girard G, Legardeur H, Mandelbrot L. Selective rather than universal screening for gestational diabetes mellitus? Eur J Obstet Gynecol Reprod Biol 2015;191:95-100. https://doi.org/10.1016/j.jogrb.2015.05.003

29. Akinci B, Celtik A, Yener S, Yesil S. Is fasting glucose level during oral glucose tolerance test an indicator of the insulin need in gestational diabetes? Diabetes Res Clin Pract 2008;82(2):219-25. https://doi.org/10.1016/j.diabres.2008.07.023

30. Agarwal MM, Punnose J, Sukhija K, Sharma A, Choudhary NK. Gestational diabetes mellitus: Using the fasting plasma glucose level to simplify the International Association of Diabetes and Pregnancy Study Groups diagnostic algorithm in an adult South Asian population. Can J Diabetes 2018;42(5):500-504. https://doi.org/10.1016/j.jcid.2017.12.009

31. Fadl $\mathrm{H}$, Östlund I, Nilsson $\mathrm{K}$, Hanson U. Fasting capillary glucose as a screening test for gestational . Fadi H, Ostlund I, Nilsson K, Hanson U. Fasting capillary glucose as a screening test for gestational
diabetes mellitus. Br J Obstet Gynaecol 2006;113(9):1067-1071. https://doi.org/10.1111/j.1471diabetes mellitus.

32. Hod M, Kapur A, Sacks DA, et al. The International Federation of Gynecology and Obstetrics (FIGO) initiative on gestational diabetes mellitus: A pragmatic guide for diagnosis, management, and care. Int J Gynecol Obstet 2015;131(Suppl 3):S173-S211. https://doi.org/10.1016/S0020-7292(15)30007-2

3. Kahn SE, Hull RL, Utzschneider KM. Mechanisms linking obesity to insulin resistance and type 2 diabetes. Nature 2006;444(7121):840-846. https://doi.org/10.1038/nature05482

34. Ng M, Fleming T, Robinson M, Thomson B, Graetz N. Global, regional and national prevalence of overweight and obesity in children and adults 1980 - 2013: A systematic analysis. Lancet 2014;384(9945):766-781. https://doi.org/10.1016/S0140-6736(14)60460-8

35. Waugh N, Pearson D, Royle P. Screening for hyperglycaemia in pregnancy: Consensus and ontroversy. Best Pract Res Clin Endocrinol Metab 2010;24(4):553-571. https://doi.org/10.1016/j. beem.2010.06.004

36. Nolan CJ. Controversies in gestational diabetes. Best Pract Res Clin Obstet Gynaecol 2011;25(1):3749. https://doi.org/10.1016/j.bpobgyn.2010.10.004

37. Mwanri AW, Kinabo J, Ramaiya K, Feskens EJM. Prevalence of gestational diabetes mellitus in urban and rural Tanzania. Diabetes Res Clin Pract 2014;103(1):71-78. https://doi.org/10.1016/j. diabres.2013.11.021

38. Chola L, Mutyambizi C, Sewpaul R, et al. Self-reported diabetes during pregnancy in the South African National Health and Nutrition Examination Survey: Extent and social determinants. BMC Pregnancy Childbirth 2017;17(1): 20. https://doi.org/10.1186/s12884-016-1218-z

39. Akinci B, Celtik A, Yener S, Yesil S. Is fasting glucose level during oral glucose tolerance test an indicator of the insulin need in gestational diabetes? Diabetes Res Clin Pract 2008;82(2):219-225, https://doi.org/10.1016/j.diabres.2008.07.023

40. Abdul-Ghani MA, DeFronzo RA. Plasma glucose concentration and prediction of future risk of type 2 diabetes. Diabetes Care 2009:32( Suppl 2):S194-S198. https://doi.org/10.2337/dc09-S309

Accepted 15 July 2019 